Article

\title{
Noise Reduction Properties of an Experimental Bituminous Slurry with Crumb Rubber Incorporated by the Dry Process
}

\author{
Moisés Bueno ${ }^{1,2, *}$, Jeanne Luong ${ }^{1,3}$, Fernando Terán ${ }^{1}$, Urbano Viñuela ${ }^{1}$, Víctor F. Vázquez ${ }^{1}$ \\ and Santiago E. Paje ${ }^{1}$
}

1 Laboratory of Acoustics Applied to Civil Engineering ( $\left.\mathrm{LA}^{2} \mathrm{IC}\right)$, Universidad de Castilla-La Mancha, Avda. Camilo José Cela s/n, 13071 Ciudad Real, Spain; E-Mails: fernando.teran@uclm.es (F.T.); urbano.vinuela@uclm.es (U.V.); victoriano.fernandez@uclm.es (V.F.V.); santiago.exposito@uclm.es (S.E.P.)

2 Road Engineering Laboratory, Empa, Swiss Federal Laboratories for Material Science and Technology, Ueberladstr. 129, CH-8600 Duebendorf, Switzerland

3 Environmental Sciences and Technologies Department, University of Liège, Passage des Déportés 2, 5030 Gembloux, Belgium; E-Mail: jeanne.luong@ulg.ac.be

* Author to whom correspondence should be addressed; E-Mail: moises.bueno@empa.ch; Tel.: +41-58-765-4386.

Received: 12 June 2014; in revised form: 29 July 2014 / Accepted: 1 August 2014 / Published: 11 August 2014

\begin{abstract}
Nowadays, cold technology for asphalt pavement in the field of road construction is considered as an alternative solution to conventional procedures from both an economic and environmental point of view. Among these techniques, bituminous slurry surfacing is obtaining an important role due to the properties of the obtained wearing course. The functional performance of this type of surfaces is directly related to its rough texture. Nevertheless, this parameter has a significant influence on the tire/road noise generation. To reduce this undesirable effect on the sound performance, new designs of elastic bituminous slurries have been developed. Within the FENIX project, this work presents the acoustical characterization of an experimental bituminous slurry with crumb rubber from wasted automobile tires incorporated by the dry process. The obtained results show that, under controlled operational parameters, the close proximity sound levels associated to the experimental slurry are considerably lower than those emitted by a conventional slurry wearing course. However, after one year of supporting traffic loads and different weather conditions, the evaluated bituminous slurry, although it conserves the original noise reduction properties in relation to the conventional one, noticeably increases the generated
\end{abstract}


sound emission. Therefore, it is required to continue improving the design of experimental surfaces in order to enhance its long-term performance.

Keywords: bituminous slurry surfacing; acoustic characterization; crumb rubber; dry process; noise reduction properties; tire/road close proximity; close proximity (CPX) method

\section{Introduction}

Cold microsurfacing and slurry surfacing are considered as one of the efficient pavement technology from both economic and ecological points of view, mainly due to their single application at low temperature. They consist of a mixture of high-quality mineral aggregate and bitumen emulsion stabilized by the addition of an emulsifier which is uniformly spread in a thin layer over a properly prepared surface. The difference between the two designs is that whereas slurry surfacing uses slightly smaller aggregates, microsurfacing can incorporate polymer modified bitumen in order to improve the cohesion of a mixture with aggregates up to $10 \mathrm{~mm}$ [1]. Traditionally, bituminous slurry has been widely used as a maintenance and rehabilitation treatments for road surfaces without structural defects to prolong the service life of the pavements, filling cracks and sealing against atmospheric agents preventing water intrusion, with a fast application process and minimal influence on the traffic. Furthermore, after improvements over several years, this cold technology is currently even used as a wearing course on roads with lower traffic requirements, offering worthy technical properties such as a high skid-resistance owing to its rough texture [2-4]. Nevertheless, the texture of a slurry wearing course is turning into a problem presenting a negative effect on the acoustic behavior, increasing impacts and vibrational mechanisms generated in the contact between tire and surface and, therefore, the emitted noise [5-8]. One solution which is being researched in order to reduce the so-called tire/road noise, is the development of more elastic surfaces to minimize the impact effect through the incorporation of crumb rubber (CR) from wasted automobile tires. In the last decades, various technical and scientific studies have reported that the addition of $\mathrm{CR}$ and other polymers improves mechanical properties of the road surface, such as permanent deformation, stiffness or reflective and thermal cracking [9-13]. Usually, the incorporation of $\mathrm{CR}$ as modifier of the bituminous binder, via the wet process, has reflected an improvement of the acoustic performance of the asphalt roads, obtaining a decreasing of the generated sound levels in relation to the percentage of rubber employed in the binder and/or the maximum aggregate size (macrotexture) used in the mixture [14-17]. Another procedure to incorporate the CR is via the dry process, partially replacing the mineral aggregates in the grading and mixing prior to the addition of the bituminous binder [11,16,18]. Different designs, such as Rubit ${ }^{\mathrm{TM}}$ in Sweden and Plusride $^{\mathrm{TM}}$ in the USA, have presented promising results reflecting a good sound behavior $[19,20]$. Although the dry process presents some advantages in relation to the wet process, concerning the cost involved and the higher amount of rubber to be used [21,22], the research has been concentrated mainly on the wet process. This choice could be explained by the irregular performance along its service life of some experimental sections with CR introduced by the dry process [23].

The present work summarizes the main results of the acoustical characterization of a test section with a new experimental design of a bituminous slurry with CR incorporated by the dry process. The study 
has been carried out by the Laboratory of Acoustics Applied to Civil Engineering (LA $\left.{ }^{2} \mathrm{IC}\right)$ of the University of Castilla-La Mancha (UCLM) through close proximity (CPX) measurements with the semi-anechoic chamber Tiresonic Mk4-LA ${ }^{2} \mathrm{IC}[16]$ over the test section during its first year of service in order to evaluate its acoustical properties.

This experimental work was performed in the area of safety and comfort in asphalt roads within the FENIX Project framework ("Strategic Research on Safer and More Sustainable Road") that has been undertaken in Spain [24]. The FENIX Project is the greatest effort in the research and development of road paving made in Europe to date. It has been structured around the following main research lines: warm mixtures, perpetual pavements, recycling (cold and hot), by-products, safety and comfort, nanomaterials, low energy consumption plants and fluidized bed.

\section{Experimental Set up}

\subsection{Test Section and Slurry Surface}

After different previous laboratory works and analysis of the obtained results, ELSAN Company layered a conventional slurry wearing course of $6 \mathrm{~mm}$ maximum aggregate size [1] from siliceous nature with a bituminous emulsion type C60BP5 MIC (CE denomination), between the KP 54+700 and the KP $70+100$ of the road CM-4106 in the region of Ciudad Real (Spain). In this road, the same slurry design with CR from waste tires as an experimental section of $400 \mathrm{~m}$ long around the KP $68+000$ was layered. The GPS coordinates of the test track are shown in Figure 1. This experimental surface incorporates $7 \%$ of CR by weight of aggregates by the dry process. The particles of rubber in the experimental design present a size inside the range of $2 / 4 \mathrm{~mm}$ and they are incorporated at ambient temperature, so none chemical reaction happens, performing only as a different fraction of the mineral aggregates. Figure 2 shows representative pictures of the surface texture of the different mixtures at the test section.

Figure 1. Location (GPS coordinates) of the test section at the road CM-4106 (Spain) with the different road surfaces evaluated.

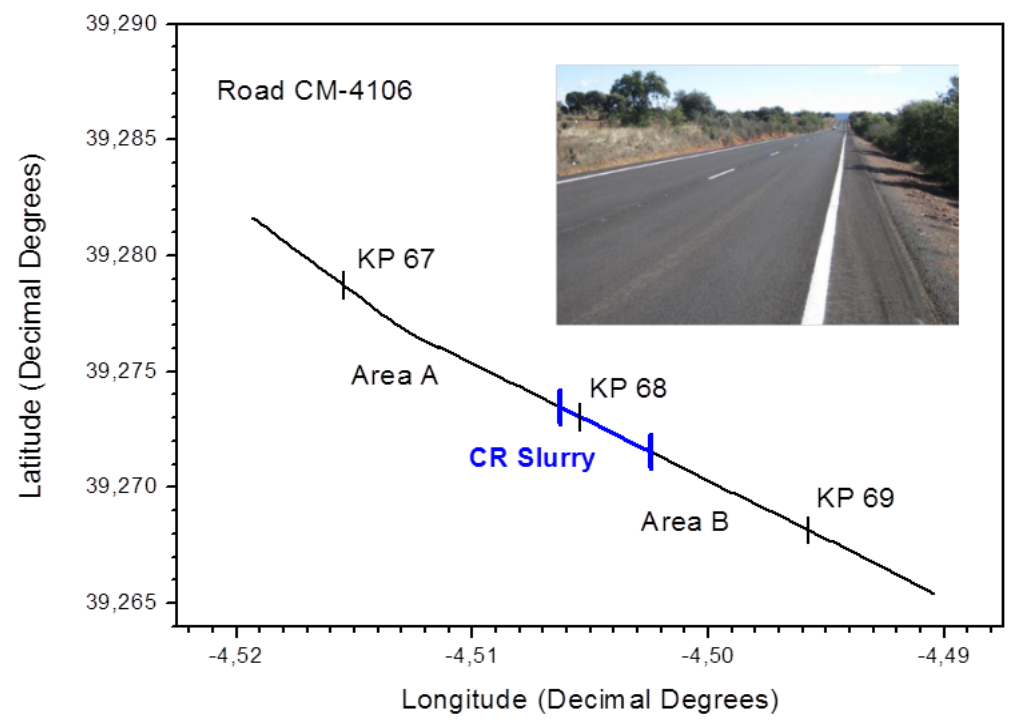


Figure 2. Representative photographs of the bituminous slurry wearing courses conventional (a) and experimental with crumb rubber (b).

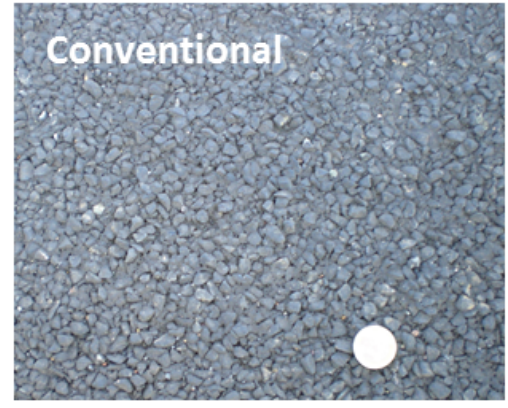

(a)

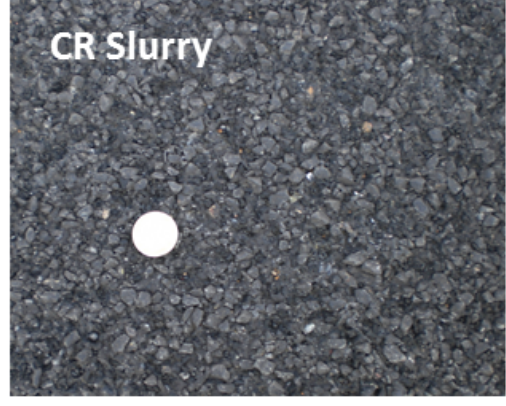

(b)

The first acoustic geo-auscultation of the experimental track with CR slurry was carried out two months after its construction and opening to traffic. Moreover, in order to assess the effect of the supported traffic on the conservation of the experimental CR surface, and thus on its acoustic behavior, another characterization was carried out one year later. Regarding this analysis it is essential to remark that the test road supports a low-traffic volume of approximately 710 vehicles per day, with $5 \%$ of these being heavy vehicles (Spanish General Road Office's database).

In acoustic characterizations of different road surfaces, the pavement temperature is one important parameter to take into account to be able to compare their noise levels. The obtained sound performance of a same surface can vary in a ratio of $0.06 \mathrm{~dB}(\mathrm{~A}) /{ }^{\circ} \mathrm{C}$ due to the influence of the surface temperature [25]. Hence, it is necessary to accomplish the acoustic characterizations at the same surface temperature or introduce a correction temperature factor for a proper comparison of the behaviors of different pavements or maintenance states. In this aspect, in the present work the two acoustic geo-auscultations were carried out at the same temperature, within a range of $17-18^{\circ} \mathrm{C}$; thus, the influence of the temperature on the analysis should be considered negligible.

\subsection{Measurement Equipment}

The measurements of the tire/road noise were carried out following the CPX methodology used in previous acoustic characterizations of road surfaces [16,25]. Trailer Tiresonic Mk4-LA ${ }^{2}$ IC (Figure 3) is made up of a semi-anechoic chamber which isolates tire/pavement sound from the external traffic or wind noises, in a frequency range of 300 to $4000 \mathrm{~Hz}$ where the traffic noise emission is focused. The CPX method provides a measure of tire/road sound levels $\left(L_{\mathrm{CPtr}}\right)$ in close proximity to the contact patch, and should provide insight into the acoustical characterization of asphalt pavements. The A-weighted pressure levels emitted by the rolling of a reference tire are continuously measured every $0.4 \mathrm{~s}$ by two BSWA MP201 1/2 in. microphones located close to the tire in the frequency range from $200 \mathrm{~Hz}$ to $16 \mathrm{kHz}$. The microphones placed inside the semi-anechoic chamber are located at a horizontal distance of $20 \mathrm{~cm}$ from the plane of the nearest tire sidewall and at a height of $10 \mathrm{~cm}$ above the road pavement surface. Front (FM) and rear (RM) microphones are positioned at angles of 45 and 135 deg to the rolling direction, respectively. A portable NI Compact Rio control and acquisition system with a four channel module and a cRio mobile module for global position determination are used to geo-register continuously the close proximity sound levels. In this study, the reference tire was a Pirelli P6000 205/55 R16 with an 
inflated pressure in cold conditions of $240 \mathrm{kPa}$. Before test measurements, the reference tire was warmed up by driving for more than $20 \mathrm{~min}$ and the sensitivity of the whole acoustic measurement set up was checked with an acoustic calibrator 4231 B\&K before and after the measurements over the tested road surface. An optical tachometer is used during the test to measure the instantaneous vehicle speed. For this evaluation, the measurements were carried out at a reference speed of $80 \mathrm{~km} / \mathrm{h}$. Knowing that the rolling speed has a high influence on the emitted sound levels, the vehicle cruise control system was used to maintain automatically the steady reference speed. Moreover, in this case, as consequence of the operational difficulties to develop the specific measurements in order to obtain an associated speed constant factor (B) for the test surfaces, a general constant $\mathrm{B}=30$ has been taken to correct the possible speed deviations of the reference speed [16,25].

Figure 3. Tiresonic Mk4-LA ${ }^{2} \mathrm{IC}$ for acoustic characterization of road surfaces and detail of the microphone positions in the close proximity of a reference tire inside the semi-anechoic chamber.
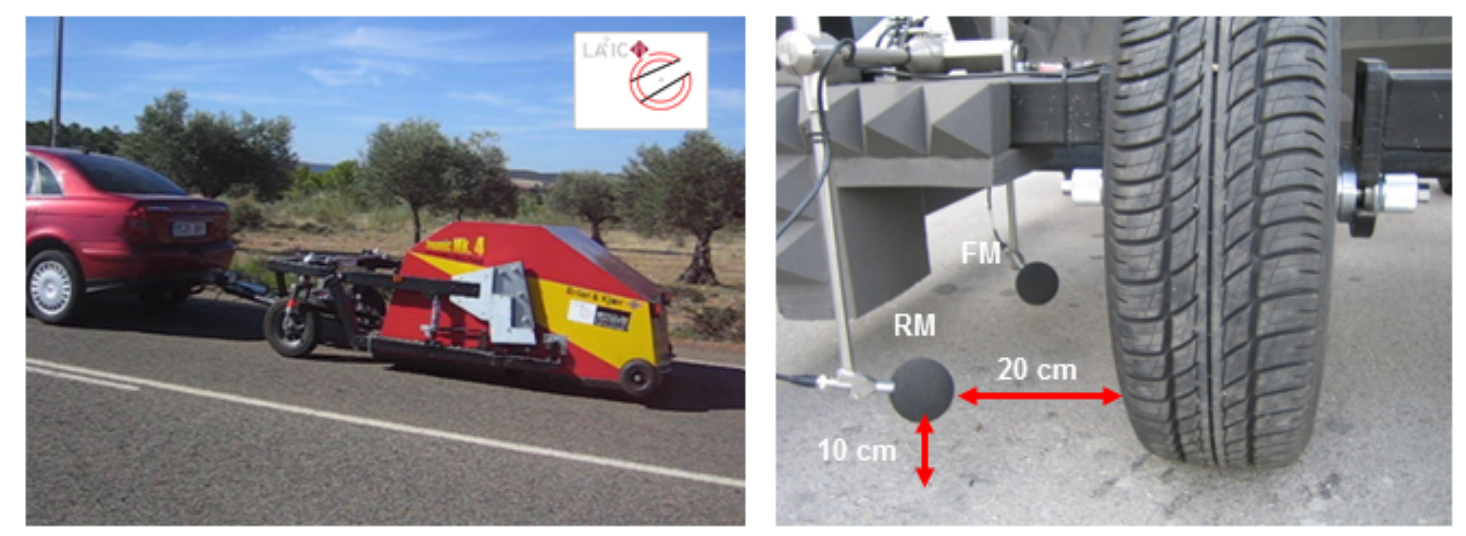

After one year, a second test of measurements was carried out in order to evaluate the evolution of the pavement. All the operational parameters were kept constant using in this analysis the same reference tire (with less than $100 \mathrm{~km}$ of working). In this second set of measurement the CPX sound levels were measured every $0.2 \mathrm{~s}$.

As the texture is one of the most important parameters in the sound emission during the interaction between the tire and the surface of the road, geo-referenced measurements of macrotexture (wavelengths ranging from $0.5 \mathrm{~mm}$ to $50 \mathrm{~mm}$ ) were also carried out to correlate them with the close proximity sound levels. The evaluation of the surface macrotexture was accomplished with a laser texture scanner system produced by Ames Engineering. The portable system is designed to measure in situ sections of pavement of $7 \mathrm{~cm} \times 10 \mathrm{~cm}$. The texture scanner is a stand-alone unit that can be placed on the surface on three point contact feet. This laser scanner allows the representative parameter MPD (Mean Profile Depth) to be measured [26] through the multiple lines scanning for the patch of surface directly under the scanner. To achieve a representative value of MPD, different measurements were carried out along the test segments, whereby global position coordinates were logged by means of an integrated GPS receiver. 


\section{Results and Discussion}

\subsection{Surface Texture}

As previously it has been said, the macrotexture is a determinant factor that has a significant effect on tire/road sound emission. In this sense, this parameter mainly affects the vibrational mechanisms, increasing or decreasing vibrations generated by the contact between tire and surface, and indirectly it could influence on aerodynamic mechanisms throughout sound dispersion phenomena. Originally, this property is related to the maximum aggregate size used in the design of the asphalt mixture. However, the lay-down of the mixture and its compaction define the final profile of the surface. Afterwards, the supported traffic as well as the weather conditions will influence on its ageing and state of conservation. Therefore, before presenting any sound result, it is important to characterize the surface texture in order to compare the different slurry surfaces studied in this work. Table 1 presents the different MPD indexes associated to the surface with $\mathrm{CR}$ and the conventional surfaces (A and B) placed just before and after the experimental section. Besides, the parameters obtained after one year for these dense surfaces are also shown.

Table 1. Mean Profile Depth (MPD) index obtained from macrotexture measurements at different points on the analyzed test sections.

\begin{tabular}{cccc}
\hline MPD (mm) & Conventional Slurry A & CR Slurry & Conventional Slurry B \\
\hline Initial & 1.25 & 2.70 & 1.50 \\
After one year & 1.20 & 2.80 & - \\
\hline
\end{tabular}

Observing the results, it is important to remark that the experimental surface presents an unusually high value compared to a conventional bituminous slurry surfaces. This fact can be due to the randomly spreading and orientation of the rubber particles in and along the surface. Attending to the evolution of the texture after one year of service life, it is also unexpected that the different evaluated surfaces conserve their macrotextures, presenting quite constant MPD results what reflects the optimal performance of this type of surfaces under traffic requirements.

\subsection{CPX Sound Levels}

In this section, the results of the measurements carried out to evaluate the influence of the CR as part of the aggregate on the acoustic behavior of the experimental bituminous slurry are presented. First of all, the evolution of the instantaneous close proximity sound levels throughout the kilometric points of the test track at a reference speed of $80 \mathrm{~km} / \mathrm{h}\left(L_{\mathrm{CPtr}, 80 \mathrm{~km} / \mathrm{h}}(t)\right)$ associated with the conventional and experimental segments are shown in Figure 4. The resulted sound profile of the slurry surface with CR can be compared with the profiles of the surfaces layered just before (A) and after (B) the experimental area. Regardless of the registered acoustical variability [27], it can be observed that the experimental CR slurry presents lower close proximity sound levels that the conventional design. Attending to the surfaces placed before and after the experimental section, it is reflected that despite being the same bituminous design, the emitted sound levels seem to be different. Usually, this difference can be due to slight differences in construction or state of conservation. In this case, it is relevant to remark that the 
section after the rubberized experimental area coincides with the access to the residence area of the closer town what implies a reduction on the driving speed. These deceleration zones have to support different traffic loads and thus, they can be worn in a different scale. Considering this fact, in this study the conventional surface before the experimental section (A) has been selected as the reference one.

Figure 4. Tiresonic Mk4-LA ${ }^{2} \mathrm{IC}$ for acoustic characterization of road surfaces and detail of the microphone positions in the close proximity of a reference tire inside the semi-anechoic chamber.

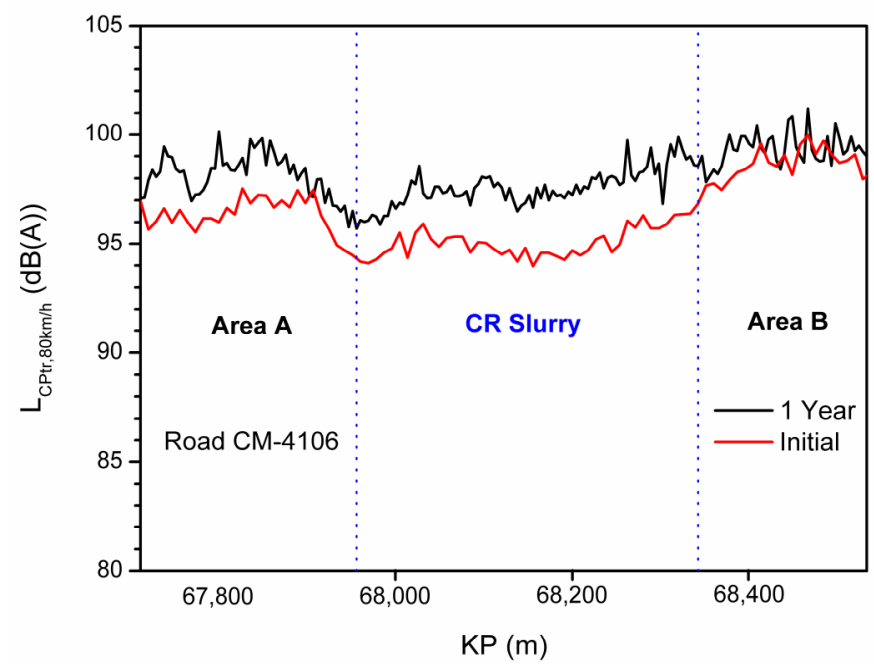

To make easier a general analysis, Table 2 summarizes the characteristic close proximity level $\left(L_{\mathrm{CPtr}, 80 \mathrm{~km} / \mathrm{h}}\right)$, the acoustical variability $(\sigma)$ and the total range of variation $(\Delta)$ of each evaluated segment. Whereas the profiles shown in Figure 4 correspond to single measurements, these characteristics parameters are obtained as average from different measurements.

Table 2. Characteristic close proximity level $\left(L_{\mathrm{CPtr}, 80 \mathrm{~km} / \mathrm{h}}\right)$, acoustical variability $(\sigma)$ and total range of variation $(\Delta)$ associated to the studied surfaces.

\begin{tabular}{ccccccccc}
\hline \multirow{2}{*}{$\mathbf{v}_{\text {ref }} \mathbf{8 0} \mathbf{~ k m} / \mathbf{h}$} & \multicolumn{3}{c}{ Initial } & & \multicolumn{3}{c}{ After One Year } \\
\cline { 2 - 3 } \cline { 7 - 9 } & $\boldsymbol{L}_{\mathbf{C P t r}} \mathbf{d B}(\mathbf{A})$ & $\boldsymbol{\sigma} \mathbf{d B}(\mathbf{A})$ & $\Delta \mathbf{d B}(\mathbf{A})$ & & $\boldsymbol{L}_{\mathbf{C P t r}} \mathbf{d B}(\mathbf{A})$ & $\boldsymbol{\sigma} \mathbf{d B}(\mathbf{A})$ & $\Delta \mathbf{d B}(\mathbf{A})$ \\
\hline Conventional slurry A (reference) & 96.6 & 0.6 & 2.0 & & 98.3 & 0.8 & 3.1 \\
CR Slurry & 95.2 & 0.8 & 2.6 & & 97.3 & 0.8 & 3.0 \\
Conventional slurry B & 98.2 & 0.9 & 3.3 & & 99.4 & 0.7 & 3.1 \\
\hline
\end{tabular}

Analyzing the characteristic acoustic parameters, it can be seen that, two months after its construction, the experimental surface with $\mathrm{CR}$ as part of aggregates generates on average $1.4 \mathrm{~dB}(\mathrm{~A})$ less than a conventional slurry design. This difference can reach values higher than $2.5 \mathrm{~dB}(\mathrm{~A})$ in some evaluated points. Although a similar effect was already obtained for gap-graded asphalt mixtures [16], now this fact confirms that slurry surfaces, which usually present poor acoustical performance due to its rough texture, can reduce the sound emission incorporating crumb rubber particles, even when the measured texture is higher.

The acoustical variability $(\sigma)$ and the total range of variation $(\Delta)$ are aspects to be considered in an acoustic assessment of pavement surfaces [16,27]. The standard deviations around the mean and the 
difference between the lowest and the highest close proximity sound levels quantify the longitudinal surface homogeneity remarking punctual differences that can be found along the test sections in order to indicate the suitability of the surface and its construction technique from acoustical standpoint. On the other hand, considering the temporal evolution, this information allows the identification of different states of maintenance of pavement surfaces. In this line, the experimental and the conventional surface present a variability less than $1.0 \mathrm{~dB}(\mathrm{~A})$ and a total range of variation around $3 \mathrm{~dB}(\mathrm{~A})$, even after one year of service. Attending to the results presented by Paje et al. [16], where different asphalt surfaces with CR were also studied, it can be observed that the evaluated bituminous slurries present a good acoustical homogeneity. However, the punctual differences along the test sections found in both studies show that the technique of incorporation of $\mathrm{CR}$ in asphalt mixtures and bituminous slurries by the dry process has to be improved.

Regularly, slurries as rolling surface are placed on roads which are not required to support heavy traffic conditions due to its special design. For this reason, a second set of measurements was carried out after one year in order to analyze the evolution of the studied surfaces and their acoustical properties. Figure 4 and Table 2 show the close proximity sound levels generated and the characteristic acoustical parameters associated to the different surfaces, respectively. The results registered after one year since the first acoustic characterization reveal that the different characteristic close proximity levels have significantly increased and the experimental rubberized slurry has lost sound reduction effect compared to the conventional surface. The original difference of $1.4 \mathrm{~dB}(\mathrm{~A})$ has been reduced to $1.0 \mathrm{~dB}(\mathrm{~A})$. The increase of the close proximity sound levels associated to the bituminous slurry with crumb rubber could be related to the loss of rubber particles from the surface [22], decreasing the damping effect over the impacts and vibrations. Nonetheless, the increase of the sound levels generated by the conventional surface and the conservation of the initial textures could be informing about the alteration of other surface properties which also influence on the acoustic performance. This fact is checked in the next section where the analysis of the sound spectra can give relevant information about the different generation mechanisms involved in the tire/road noise.

\subsection{CPX Sound Spectra}

In this section, In order to understand the mechanisms related to the interaction between the reference tire and the evaluated surfaces, the sound emission during the rolling process at $80 \mathrm{~km} / \mathrm{h}$ was analyzed in 1/3-octave band between $200 \mathrm{~Hz}$ and $16 \mathrm{kHz}$. Analyzing these sound spectra, the influence of the two main groups of mechanisms on the sound generation can be determined, since impacts and vibration mechanisms are related to low and medium frequencies (below $1 \mathrm{kHz}$ ) and aerodynamic mechanisms are associated to higher frequencies (above $1 \mathrm{kHz}$ ). In this sense, Figure 5 presents the characteristic close proximity sound spectra associated to the experimental and the conventional surfaces. It can be observed that the incorporation of CR have no significant effect on sound levels at frequencies above $1 \mathrm{kHz}$, usually associated to air-pumping and other mechanisms related to the flow of air in and around the tread grooves of the tires, what was expected since both of them are dense surfaces. Nevertheless, noticeable differences are found in the range below $2 \mathrm{kHz}$, such as those found in other asphalt surfaces with CR added by the dry process [16]. In this area, related to vibrational mechanisms, the CPX sound levels emitted by the rubberized slurry are lower than those emitted by the conventional surface. Therefore, it 
can be concluded that the reduction of the impacts effect, due to crumb rubber incorporation, can be the main reason for the decrease in the sound emission generated over the experimental surface [28].

Figure 5. Comparison of the representative close proximity noise spectra of the different test sections for the reference speed $\left(\mathrm{v}_{\text {ref }}=80 \mathrm{~km} / \mathrm{h}\right)$.

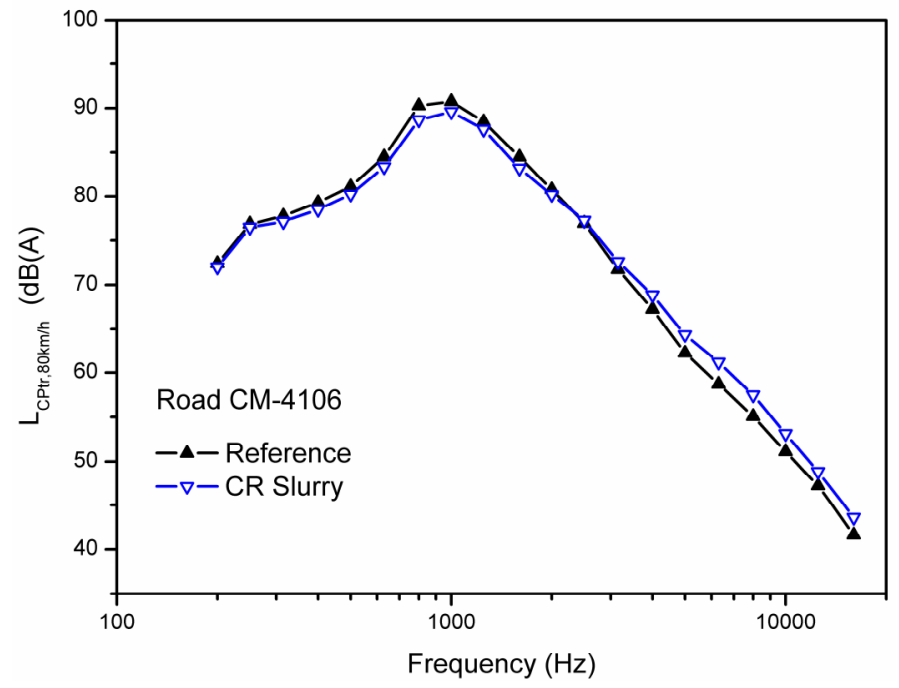

The evolution of the generation mechanisms after one year of service has been also analyzed. In this sense, in Figure 6 the first obtained close proximity sound spectrum associated to the surface with CR is compared to the spectrum obtained from the second set of measurements. Analyzing the figure, it can be observed that the shape of the spectra is quite similar, but after one year, the intensity of the close proximity levels has increased along the evaluated range of frequencies. This means that the ageing has effect on the different generation and propagation mechanisms. Previous studies [13] have reported that the addition of CR to asphalt mixes, especially by the dry process, increases their stiffness modulus. In this line, the obtained results indicate that it is possible that a higher stiffness due to ageing can be the surface property with more influence on the acoustic performance of the slurry surfaces evaluated in this study.

Figure 6. Time evolution of tire/road noise. Spectra at a reference speed of $80 \mathrm{~km} / \mathrm{h}$ associated to the experimental bituminous slurry with crumb rubber.

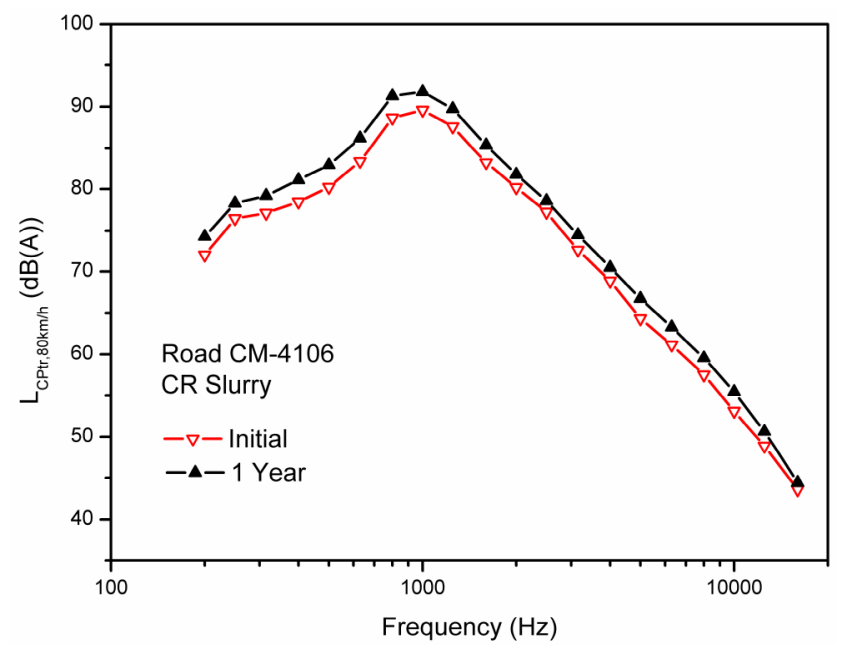




\section{Conclusions}

The analysis of the results obtained from the acoustic characterization of a new design of bituminous slurry, which incorporates crumb rubber by the dry process, as experimental wearing course has been presented in this work. Two different sets of measurements were carried out with the trailer Tiresonic Mk4-LA ${ }^{2} \mathrm{IC}$ in order to evaluate the close proximity sound generated by the interaction between the reference tire and the rubberized slurry and its temporal evolution after one year of traffic service. The results show that the experimental slurry emits lower close proximity sound levels at $80 \mathrm{~km} / \mathrm{h}$ compared to the conventional surface. Analyzing the mechanisms of generation by means of the associated sound spectra, it can be observed that, despite presenting a rougher surface macrotexture, the studied surface with crumb rubber has a considerable influence on the vibration mechanisms reducing the effect of the impacts. This aspect reflects that the improvement of the acoustic performance is related to the incorporation of crumb rubber since a more elastic wearing course is obtained. The second set of measurements carried out after one year indicates that the noise reduction properties of the rubberized slurry in relation to the conventional surface are kept quite constant, decreasing the original difference from $1.4 \mathrm{~dB}(\mathrm{~A})$ to $1.0 \mathrm{~dB}(\mathrm{~A})$. Nevertheless, it seems important to remark that the close proximity sound levels registered have significantly increased. Considering that the shapes of the associated sound generation spectra are quite similar and the macrotexture presents constant values, and that the different measurements were accomplished under controlled operational parameters (measurement equipment and temperature), it is possible that the increase of the sound levels is related to an increase of the surface stiffness due to an early ageing.

Thus, once the feasibility of the new design with crumb rubber as alternative to the conventional slurry surfacing has been checked, it is necessary to study in more detail its long-term performance and where to place these special surfaces. Furthermore, new experimental designs with varying size and content of crumb rubber, bituminous emulsions or even subgrades layers are required to investigate their influence in order to enhance the acoustic performance.

\section{Acknowledgments}

The authors would like to thank to the Spanish Centre for the Development of Industrial Technology (CDTI) for its support in the development of the FENIX Project "Strategic Research on Safer and More Sustainable Roads" within the framework of the Ingenio 2010 program (www.proyectofenix.es) as well as to the Spanish Ministry of Economy and Competiveness for the project BIA 2012-32177 within the framework of the National Plan for Scientific Research through European Regional Development Funds.

\section{Author Contributions}

Experimental measurements, analysis and interpretation of the results as well as conclusions have been conducted by all the co-authors. The manuscript has been written by M.B. with revision and approval by the others co-authors.

\section{Conflicts of Interest}

The authors declare no conflict of interest. 


\section{References}

1. UNE-EN 12273:2009 Slurry Surfacing Requirements; European Committee for Standardization: Brussels, Belgium, 2009.

2. Smith, R.E.; Beatty, C.K. Microsurfacing usage guidelines. Transp. Res. Rec. 1999, 1680, 13-17.

3. Nebrada-Rodrigo, F.J.; Santos, J. Slurry seal and microsurfacing (Lechadas bituminosas y microaglomerados en frío). Carreteras 2005, 4, 78-87. (In Spanish)

4. Van Kirk, J. Multi-layer pavement preservation strategies using slurry surfacing and chip seals. In Proceedings of the 7th ISSA World Congress, Lyon, France, October 2010.

5. Sandberg, U.; Ejsmont, J.A. Tyre/Road Noise Reference Book; Informex: Kisa, Sweden, 2002.

6. Mun, S.; Cho, D.S.; Choi, T.M. Influence of pavement surface noise: The Korea highway corporation test road. Can. J. Civil Eng. 2007, 34, 809-816.

7. Ahammed, A.M.; Tighe, S.L. Pavement surface friction and noise: Integration into the pavement management system. Can. J. Civil Eng. 2010, 37, 1331-1340.

8. Wang, G.; Smith, G.; Shores, R. Pavement noise investigation on North Carolina highways: An on-board sound intensity approach. Can. J. Civil Eng. 2012, 39, 878-886.

9. Takallou, H.B.; Rayner, G.L.; Takallou, M.B. Development of design and construction guidelines for rubberized emulsified asphalt slurry seal. In Proceedings of the 4th ISSA World Congress, Paris, France, March 1997.

10. MacLeod, D.; Ho, S.; Wirth, R.; Zanzotto, L. Study of crumb rubber materials as paving asphalt modifiers. Can. J. Civil Eng. 2007, 34, 1276-1288.

11. Hernández-Olivares, F.; Witoszek-Schultz, B.; Alonso-Fernández, M.; Benito-Moro, C. Rubber-modified hot-mix asphalt pavement by dry process. Int. J. Pavement Eng. 2009, 10, 277-288.

12. Pasquini, E.; Canestrari, F.; Cardone, F.; Santagata, F.A. Performance evaluation of gap graded asphalt rubber mixtures. Constr. Build. Mater. 2011, 25, 2014-2022.

13. Moreno, F.; Rubio, M.C. Influence of crumb rubber on the indirect tensile strength and stiffness modulus of hot bituminous mixes. J. Mater. Civil Eng. 2012, 24, 715-724.

14. Miró, R.; Pérez-Jiménez, F.; Martínez, A.H.; Reyes, O.; Paje, S.E.; Bueno, M. Effect of using crumb rubber bituminous mixes on functional characteristics of road pavements. Transp. Res. Rec. 2009, 2126, 83-90.

15. Ahammed, A.M.; Tighe, S.L.; Klement, T. Quiet and durable pavements: Findings from an Ontario study. Can. J. Civil Eng. 2010, 37, 1035-1044.

16. Paje, S.E.; Bueno, M.; Terán, F.; Miró, R.; Pérez-Jiménez, F.; Martínez, A.H. Acoustic field evaluation of asphalt mixtures with crumb rubber. Appl. Acoust. 2010, 71, 578-582.

17. Freitas, E.F. The effect of time on the contribution of asphalt rubber mixtures to noise abatement. Noise Control Eng. J. 2012, 60, 1-8.

18. Pasetto, M.; Spinoglio, S. The use of a synthetic aggregate in non-skid and noise abatement microsurfacings for road maintenance. Performance improvements and environmental impact. In Proceedings of the 4th ISSA World Congress, Paris, France, March 1997.

19. Esch, D.C. Construction and benefits of rubber modified-asphalt pavements. Transp. Res. Rec. 1982, 1680, 13-17. 
20. Amirkhanian, S.N.; Arnold, L.C. A Laboratory and Field Investigation of Rubberized Asphalt Concretes Mixtures (Pelham road); Final Report No. FHWA-SC-93-02; South Carolina Department of Highways and Public Transportation: South Carolina, SC, USA, 1993.

21. Cao, W. Study on properties of recycled tire rubber modified asphalt mixtures using dry process. Constr. Build. Mater. 2007, 21, 1011-1015.

22. Moreno, F.; Rubio, M.C.; Martinez-Echevarría, M.J. The mechanical performance of dry-process crumb rubber modified hot bituminous mixes: The influence of digestion time and crumb rubber percentage. Constr. Build. Mater. 2012, 26, 466-474.

23. Emery, J. Evaluation of rubber asphalt demonstration projects. Transp. Res. Rec. 1995, 1515, 37-46.

24. Centre for the Development of Industrial Technology (CDTI). 2009. FENIX Project. Strategic Research on Safer and More Sustainable Roads. Available online: http://www.proyectofenix.es/ (accessed on 4 August 2014).

25. Bueno, M.; Luong, J.; Viñuela, U.; Terán, F.; Paje, S.E. Pavement temperature influence on close proximity tire/road noise. Appl. Acoust. 2011, 72, 829-835.

26. EN ISO 13473-1:2004 Characterization of Pavement Texture by Use of Surface Profiles. Part 1: Determination of Mean Profile Depth; European Committee for Standardization: Brussels, Belgium, 2004.

27. Paje, S.E.; Bueno, M.; Terán, F.; Viñuela, U. Monitoring road surfaces by close proximity noise of the tire/road interaction. J. Acoust. Soc. Am. 2007, 122, 2636-2641.

28. Biligiri, K.P.; Kalman, B.; Samuelsson, A. Understanding the fundamental material properties of low-noise poroelastic road surfaces. Int. J. Pavement Eng. 2013, 14, 12-23.

(C) 2014 by the authors; licensee MDPI, Basel, Switzerland. This article is an open access article distributed under the terms and conditions of the Creative Commons Attribution license (http://creativecommons.org/licenses/by/3.0/). 